\title{
Energy saving through passive cooling measures using bags with sawdust
}

\author{
V K Bajpai
}

\section{S Kumar}

K S Kasana

All of the Faculty of Mechanical Engineering, National Institute of Technology, Kurukshetra (Haryana), India

\begin{abstract}
In recent times, due to limited availability of energy from conventional sources, its effects on the environment (depletion of the ozone layer and an increase in the average temperature of the earth) and their rising prices has drawn the attention of engineers and scientists, throughout the world. The need is being felt to conserve conventional sources of energy or to depend less and less on these sources of energy. One area, where considerable amount of energy is consumed is in creating comfort conditions in residential buildings. In the present work, a passive measure has been used to create comfort conditions in buildings using low cost material in summer. The comfort index used is 'Tropical Summer Index'. In the test room of size (length $=7.8 \mathrm{~m}$, breath $=6 \mathrm{~m}$, and height $=3.8 \mathrm{~m}$ ), three fans are needed consuming about 225 watthour of electrical energy to keep the room in the comfort zone. This will eliminate the use of an air conditioner, which consumes a much larger amount of about 4 tons of refrigeration ( $15 \mathrm{~kW}$ ). For residential buildings with smaller rooms, the number of fans required will be less. By adopting this measure, the use of an air conditioner can be avoided leading to a saving of electrical energy. It has been observed that during the summer season in India, present passive measures keep the room air conditioned well, within the comfort zone by using a meagre amount of electrical energy.
\end{abstract}

Keywords: air-conditioner, passive cooling, energy saving, air temperature, comfort zone, sawdust bags, Tropical Summer Index

\section{Introduction}

In the present conventional energy scenario and its effects on the environment, the emphasis of researchers is on conservation of conventional sources of energy, and focus on the measures using minimum or no energy (Fatih \& Argiri 1999). One area where energy can be saved is to provide comfort conditions in buildings (Healy and Clinch 2002) Before invention of mechanical means to provide comfort conditions, people used to make their dwellings in a way, which were comfortable to live in, and were dependent on natural means (Tiwari 2001). In buildings built during the Mughal period, extensive use of thick walls, high ceilings, domed tops, shading of external surfaces, water channels etc. can be found (Bahadori \& Fariborz 1986). Today people depend more on mechanical means to provide comfort conditions in their dwellings, and natural means to provide comfort conditions have thus been neglected. Unintelligent use of energy is not only depleting the conventional sources of energy but also disturbing the nature which ultimately leads to natural calamities. It is the demand of the time to depend less and less on conventional sources of energy and explore non-conventional and environmental friendly energy sources. Reduction of energy use to provide comfort conditions in buildings can be achieved by using passive comfort techniques (Abel 1994; Agarwal \& Verma 1970; Bajpai 1985; Chandra 1983; Maheshwari, Al-Ragom, \& Suri 2001).

The heat transfer through walls, roofs and other openings along with internal heat gains like occupants, lights, appliances, machines, piping etc, determine temperature inside a room. Control of this heat transfer basically depends on the thermal behaviour of the building material. It has been found that maximum percentage of heat flow to the building is through the roof only and hence appli- 
cation of passive measures on a roof are more relevant (Kumar, Singh \& Sharma, 1990).

This paper attempts to provide an evaluation of an application of low cost passive measures. Measure chosen is simple in nature, and very easy to use. By using this measure, the energy expenditure to provide comfort conditions can be reduced and thus can contribute to the conservation of valuable energy. The passive measure used is bags filled with a thin layer of saw dust followed by spray of water on the roof. Water gets cooled due to evaporation. Bags within a layer of saw dust act as the heat sink for the falling radiations and hot air blowing over the roof, due to which temperature at the surface of roof is lowered, which reduces temperature of air inside the room.

\section{Experimental set up and instrumentation}

Through an experimental set up as described below, observations were taken during peak summer season. The effectiveness of the measure was evaluated by making a comparison between the room air temperature of a treated room with passive measures applied on its roof and an untreated room without passive measures. For this purpose, two similar lab rooms were selected. Both rooms had the same orientation, built of the same materials, same surroundings and have the same dimensions.

These rooms are single storey structures with the roof exposed to sun. Corridors are provided on the east and south sides and, on the west side, there is an adjoining room. No direct radiations reach from these three sides i.e. east, west and south. Direct radiations on the north wall are almost negligible. $62 \%$ of the area of the north wall is of glass. There are three window openings in the glass area. There is only one door in the south wall. The treated room had the entire roof covered with bags filled with sawdust in such a manner that it had uniform thickness (see Figure 1).

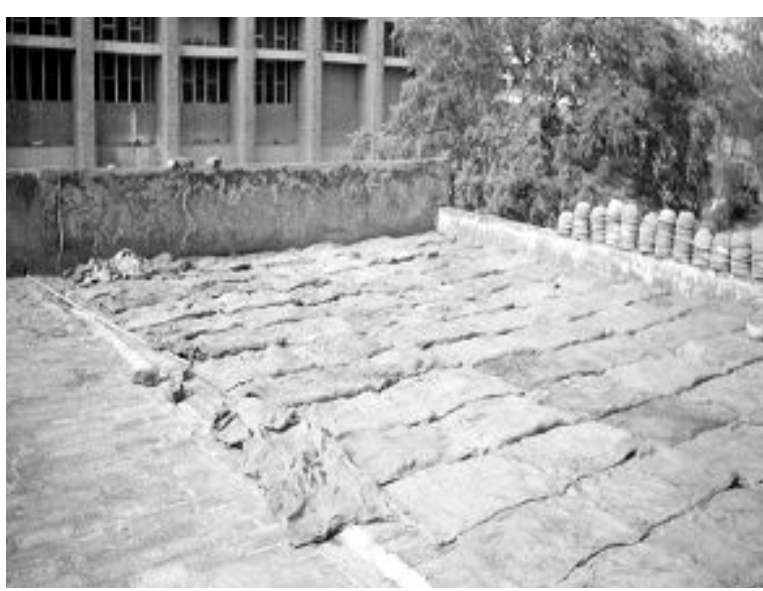

Figure 1: Roof treated with sacks filled with sawdust
Sawdust is hygroscopic in nature. It controls the rate of vaporisation of water, which migrates to atmosphere due to vapour pressure differential. Water was sprinkled on it in the morning. Since, saw dust has good retentivity for water there is no need for sprinkling the water again and again. Due to evaporation of water, the temperature of water in the bags is decreased. Also, direct radiation does not reach on the roof as these are absorbed by the water in the bags. Bags used act as a heat sink both for radiation and heat from the roof.

In order to study the effectiveness of passive measure observations of room air temperature, this has been undertaken with the help of thermocouples. The variation in temperature for a treated / untreated room was recorded with the help of a data logger. Other related parameters, namely, relative humidity and wind velocity were also observed. The instruments used were an anemometer and a hygrometer. An anemometer was used to measure the wind velocity. It was a simple instrument with a feather light bladed rotor housed in needle bearings. The instrument could measure wind velocity ranging between $1 \mathrm{~m} / \mathrm{s}$ to $15 \mathrm{~m} / \mathrm{s}$. The hygrometer has been used to measure the relative humidity, calibrated directly in percentage.

\section{Results and discussion}

The air temperatures in test rooms were observed in June for every two hours from zero hours midnight to 2400 hours (next day) for both treated as well as untreated rooms (see Table 1 and Figure 2). The observations for a typical hot day have been given in this paper.

Table 1: Roof treated with bags with sawdust

\begin{tabular}{ccccc}
\hline $\begin{array}{c}\text { Time in } \\
\text { hours }\end{array}$ & $\begin{array}{c}\text { Inside } \\
\text { surface } \\
\text { termp. }\end{array}$ & $\begin{array}{c}\text { Untreated } \\
\text { room air } \\
\text { temp. }\end{array}$ & $\begin{array}{c}\text { Outside } \\
\text { room air } \\
\text { temp. }\end{array}$ & $\begin{array}{c}\text { Treated } \\
\text { room air } \\
\text { temp. }\end{array}$ \\
\hline 0000 & 33.30 & 35 & 24.6 & 30.6 \\
\hline 0200 & 33 & 34.3 & 22.4 & 30.1 \\
\hline 0400 & 32.8 & 34.2 & 23.9 & 29.9 \\
\hline 0600 & 32.2 & 34.5 & 28.2 & 29.7 \\
\hline 0800 & 32.4 & 34.6 & 30.9 & 29.5 \\
\hline 1000 & 32.5 & 34.8 & 31.9 & 30.4 \\
\hline 1200 & 32.6 & 35 & 35.0 & 30.5 \\
\hline 1400 & 32.7 & 35.4 & 38 & 30.6 \\
\hline 1600 & 33 & 35.6 & 36.6 & 31.0 \\
\hline 1800 & 33.2 & 35.8 & 28 & 31.6 \\
\hline 2000 & 33.3 & 35.9 & 26.8 & 31.8 \\
\hline 2200 & 33.5 & 36 & 22.6 & 31.3 \\
\hline 2400 & 33.4 & 35.5 & 22 & 31.0 \\
\hline
\end{tabular}

On comparing the room air temperature of treated and untreated rooms, it could be observed that the air temperature in the treated room remained 


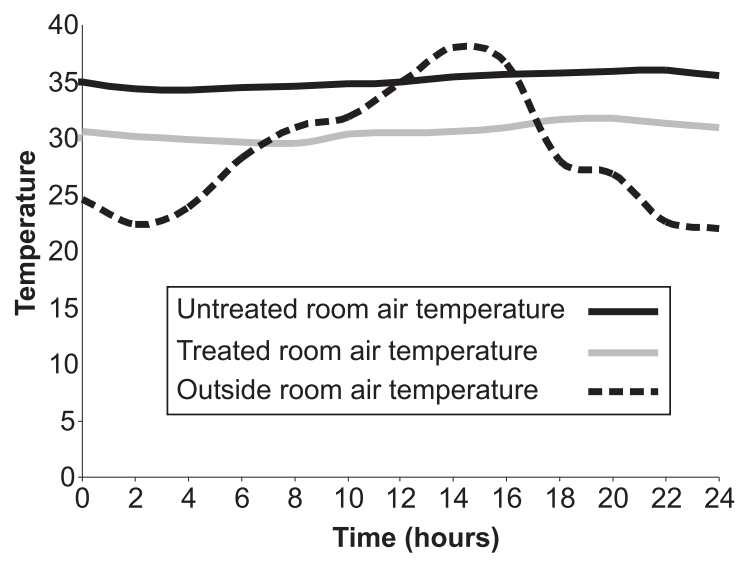

Figure 2: Temperature variation for treated, untreated and outside air

lower throughout 24 hours of the day. At 0600 hours, when the minimum temperature of the day was expected, the observed air temperature of the treated and untreated room was $29.7^{\circ} \mathrm{C}$ and $34.5^{\circ} \mathrm{C}$ respectively. Similarly, at 1800 hours, the two temperatures were $31.9^{\circ} \mathrm{C}$ and $36.5^{\circ} \mathrm{C}$ respectively.

The treatment reduced the temperature of the room by $4.5^{\circ} \mathrm{C}$ during peak hot hours during the day. From 1000 hours to 1800 hours, the period, which was quite uncomfortable during summer season, the reduction in temperature due to treatment, varied between 4.0 to $4.5^{\circ} \mathrm{C}$. At 0200 hours, the observed temperatures of the untreated room were $34.3^{\circ} \mathrm{C}$ and that of treated room was $30.1^{\circ} \mathrm{C}$, indicating a difference of $4.2^{\circ} \mathrm{C}$. At 2200 hours, the two temperatures were $36^{\circ} \mathrm{C}$ and $31.3^{\circ} \mathrm{C}$ showing a difference of $4.7^{\circ} \mathrm{C}$. At zero hours this difference in temperature was $4.4^{\circ} \mathrm{C}$.

The roof because of its maximum exposure to solar radiation throughout the day contributed a maximum heat load to the room (Kumar 1995). Sawdust filled bags prevented the direct exposure of the roof to the sun. It reduced heat flow through it. Also, the dry roof gets heated three times as compared to the same volume of water. Water also loses some of its heat by evaporation, which is not possible with a dry roof. A given amount of solar radiation will therefore the heat dry roof to a higher temperature than it will heat water in sawdust. Also, air in contact with the dry roof will be heated to a higher temperature. The above factors moderated the variation in room air temperature and also lowered the total heat load.

\section{Comfort zone and treated room air conditioned}

The values of relative humidity in summer, during the period of observations, vary between $62 \%$ to $64 \%$ (see Table 2). The comfort zone for summer on the psychrometric chart (see Figure 3) shows that for relative humidity between $30 \%$ to $70 \%$, a person is comfortable between tropical summer indexes of $25^{\circ} \mathrm{C}$ to $30^{\circ} \mathrm{C}$ at zero air velocity. The comfort zone shown is relevant to Indian climatic conditions (Olesen (2000); Sharma (1977)). The average value of the tropical summer index for the treated room is $30.6^{\circ} \mathrm{C}$ and, as such, does not fall in the comfort zone. As given in the comfort chart, air velocity of $0.5 \mathrm{~m} / \mathrm{s}-1.0 \mathrm{~m} / \mathrm{s}$ decreases the tropical summer index by $1.4^{\circ} \mathrm{C}$ to $2^{\circ} \mathrm{C}$.

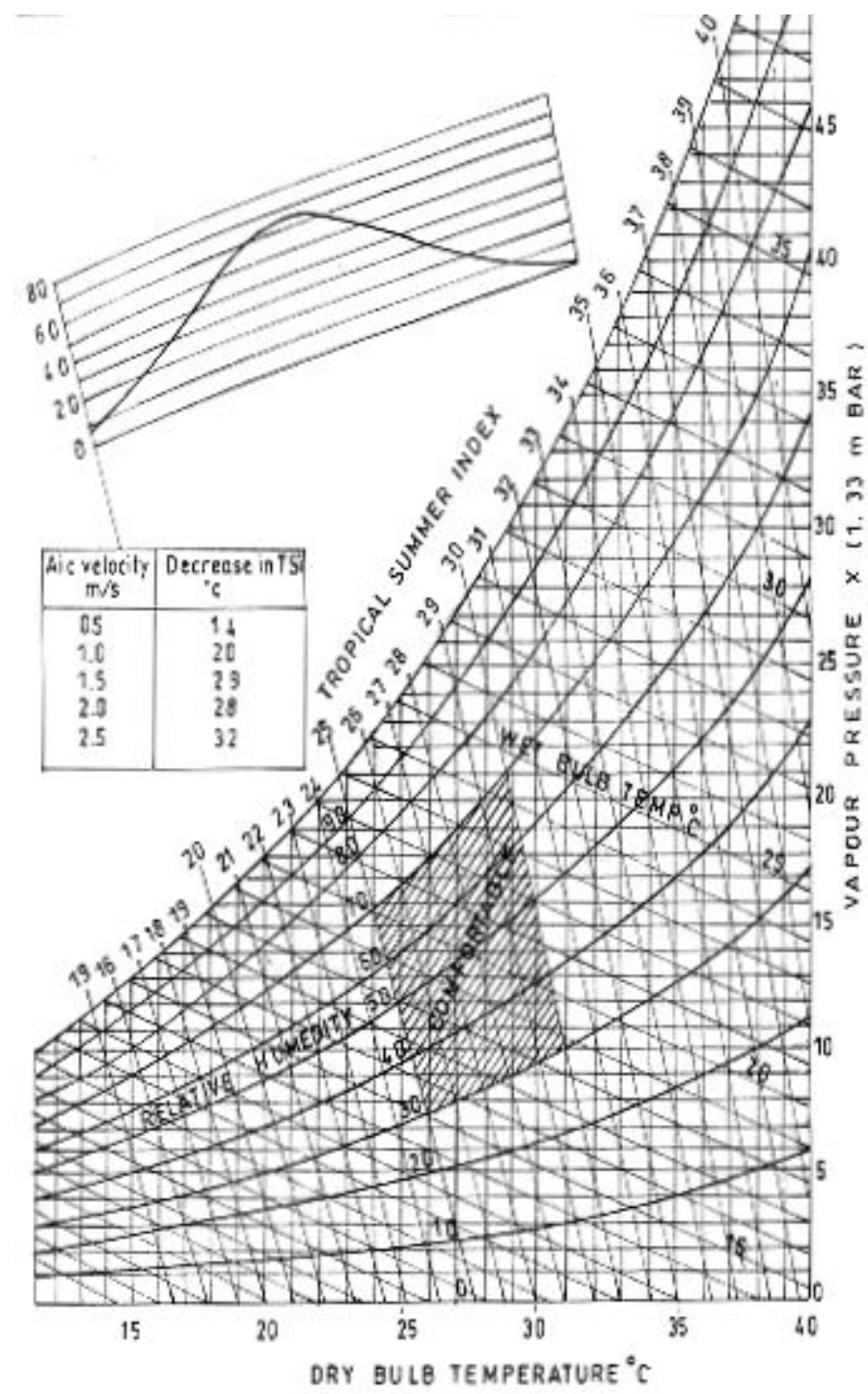

Figure 3: Comfort zone for summer on psychrometric chart

If we provide the movement of air at $0.5 \mathrm{~m} / \mathrm{s}$ $1.0 \mathrm{~m} / \mathrm{s}$ in the treated room, the tropical summer index of the treated room decreases to a value of $28^{\circ} \mathrm{C}$, which is well within the comfort zone for given humidity range. This movement can be provided by an ordinary ceiling fan. The velocity profile of air created by the fan is given in literature (Cook, 1989). One fan covers approximately an area of $19 \mathrm{~m}^{2}$ hence in the treated room whose area is $46 \mathrm{~m}^{2}$, three fans will have to be used to create air movement at a desirable velocity. One fan consumes about 75 watt-hour of electrical energy and 
hence about 225 watt-hour of electrical energy will be consumed.

Table 2: Values of relative humidity observed on a typical summer day

\begin{tabular}{cc}
\hline Time (hours) & $\begin{array}{c}\text { Relative humidity } \\
\text { in summer }\end{array}$ \\
\hline 0 & 62 \\
\hline 2 & 62 \\
\hline 4 & 62 \\
\hline 6 & 62 \\
\hline 8 & 64 \\
\hline 10 & 64 \\
\hline 12 & 64 \\
\hline 14 & 64 \\
\hline 16 & 63 \\
\hline 18 & 62 \\
\hline 20 & 62 \\
\hline 22 & 62 \\
\hline
\end{tabular}

\section{Conclusions}

It has been observed that the average temperature of the untreated room during the period of observation was $35^{\circ} \mathrm{C}$, and that the average temperature of the treated room was $30.6^{\circ} \mathrm{C}$, showing a difference of $4.4^{\circ} \mathrm{C}$. The tropical summer index for the treated room does not lie in the comfort zone.

By introducing an air movement of $0.5-1.0 \mathrm{~m} / \mathrm{s}$ with the help of fans, the tropical summer index can be lowered to a value of about $28^{\circ} \mathrm{C}$. This falls well within the comfort zone. In the test room, which is quite large (length $=7.8 \mathrm{~m}$, breath $=6 \mathrm{~m}$, height $=$ $3.8 \mathrm{~m}$ ), three fans are needed consuming about 225 watt-hour of electrical energy. This will eliminate the use of an air conditioner, which consumes a much larger amount of about 4 tons of refrigeration (15 $\mathrm{kW})$. For residential buildings with smaller rooms, the number of fans required will be less. By adopting this measure, the use of an air conditioner can be avoided leading to saving of electrical energy.

\section{References}

Agarwal K.N. and Verma V.V., 1970. Suitability of ricehusk and sawdust as a cold storage insulation. Building Digest (85) Central Building Research Institute Roorkee, India.

Bahadori, M.N. and Haghighat Fariborz, 1986. Thermal performance of adobe structures with domed roofs and moist internal surfaces. Solar Energy, Vol. 36, No.4, pp. 365-375.

Bajpai S.C., 1985. An active and passive solar house, International Journal of Ambient Energy, Vol.6, No. 1, pp. 25-30.
Birol, F. and Argiri, M.,1999. World energy prospects to 2020. Energy, Vol. 24, pp. 905-918.

Cook, J., 1989. Passive cooling. MIT Press, Cambridge Massachusetts.

Enno, A. 1994. Low-energy buildings. Energy and Buildings, Vol.21, pp. 169-174.

Healy, J.D. and Peter Clinch J., 2002. Fuel poverty, thermal comfort and occupancy: results of a national household survey in Ireland. Applied Energy, Vol.73, pp. 329-343.

Kumar, S., 1995. Evaluation of some passive cooling measures for residential buildings. Ph.D. Thesis, KU Kurukshetra.

Kumar, S., Singh, G. and Sharma, J.K., Analytical study of some passive cooling measures using $\mathrm{r}$-c network. Journal of IE (I), Vol. 71, July 1990.

Maheshwari G.P., Al-Ragom F. and Suri R.K., 2001. Energy-saving potential of an indirect evaporative cooler. Applied Energy, Vol. 69, No 1, pp. 69-66.

Olesen Bjarne, W., 2000. Guidelines for comfort, ASHRAE Journal, pp. 41-46.

Piyush, T. 2001. Energy efficiency and building construction in India. Building and Environment, Vol. 36, No. 10, pp.1127-1135.

Sharma M.R., 1977. A study of the thermal effects of climate and building on human comfort with special reference to India. Ph.D. thesis, Agra University, Agra, India.

Subhash, C., 1983, Temperature control in a building with evaporative cooling and variable ventilation. Solar Energy, Vol. 30, No.4, pp. 381-387.

Received 15 February 2005; revised 15 August 2005 